\title{
Comparative Study of Linear and Nonlinear Seismic Behavior of Non-Isolated, Base-Isolated and Top Floor (TMD-Type) Isolated Structural Frames
}

\author{
Hamidreza Baghaei ${ }^{1, *}$, Reza Razani ${ }^{2}$ \\ ${ }^{1}$ Civil Engineering Faculty, Islamic Azad University of Tehran- South Branch, Tehran, Iran \\ ${ }^{2}$ Civil Engineering Faculty, Shiraz University, Shiraz, Iran
}

Copyright $\bigcirc 2019$ by authors, all rights reserved. Authors agree that this article remains permanently open access under the terms of the Creative Commons Attribution License 4.0 International License

\begin{abstract}
In this study, the linear and nonlinear seismic behavior of a $2 \mathrm{D}$ ten story steel model frame is investigated in four cases: Without Isolation (WI), Base Isolation (BI), Roof Isolation (RI) and Two Top Floor Isolation (2TFI). Friction Pendulum System (FPS) is used for base and top floor isolations. First, the selected model without any isolation was used as a base for comparison of the seismic behavior of models. For dynamic analysis two types of base acceleration was used namely: 1- $1979 \mathrm{El}$ Centro earthquake, 2- A newly proposed base acceleration similar to displacement oscillation proposed in FEMA 461 code. In the two cases, the maximum equivalent standard acceleration at DBE level spectrum with duration of 8 seconds was used. For the WI frame Nonlinear Statical Analysis (Pushover or POA) was used by applying UBC-97 loading code. The concluding result shows that in linear and nonlinear ranges BI frame shows comparatively superior seismic behavior for MCE and DBE earthquake levels. Results of POA of WI frame according to UBC-97 code shows better behavior than that of dynamical analysis. RI frame in nonlinear range shows better behavior than WI frame using POA. Two Top Floor Isolation frame shows better behavior both in linear and nonlinear ranges compared to both RI and WI frames. The details of the behavior of all frames are shown in various diagrams.
\end{abstract}

Keywords Base Isolation, Top Floor Isolation as TMD, Friction Pendulum Isolator, Nonlinear Dynamic Analysis

\section{Introduction}

During recent decade, the design and development of Base Isolation and Top Floor Isolation in seismic design of building have been subjected of various studies where successful applications of the isolation concept in various developed country are reported in references $[1,2]$.

Many researchers have studied the technical advantages, disadvantages and economy of using Base Isolation and Top Floor Isolation as compared to Without Isolation system $[2,3]$. The purpose of this study is to investigate three issues:

1. Comparison of seismic behavior (total and relative lateral drifts, shear of floors) using conventional linear analysis for four types of frames namely: Base Isolation (BI), Roof Isolation (RI), Two Top Floor Isolation (2TFI) and Without Isolation (WI) of a ten story 2D steel frame used as model frame structure.

2. The second objective of this paper is to compare the seismic behavior of model structure under non-linear static and dynamic analyses to find out more realistic behavior of the isolated frames (BI, RI and 2TFI) vs. WI frame under given loading conditions in particular from point of performance based design for low-rise, conventional, regular and fixed base structures. Most engineers use Non-linear Statical Analysis (NSA) method for analysis of non-isolated structure which is called Pushover Analysis (POA). This approximate method uses code specified fictitious load patterns such as the one given in UBC-97 code which is applied to various floors of the structure with step-wise uniform increase of amplitude until the structure collapses or reaches a specified roof displacement. Various methods of POA has been developed such as Modal POA [4,5], load modified POA, etc... [6], which their advantages and disadvantages are discussed by various investigators [7]. In nonlinear range POA method has important shortcomings for irregular structures especially for base or floor isolated building, because the pattern or form of loading along the height of structure depends on total and relative stiffness of floors which changes significantly in nonlinear range as various plastic hinges develop gradually in various stories and location of the structure and produce local softness as loading time advances [8]. 
Comparative Study of Linear and Nonlinear Seismic Behavior of Non-Isolated,

Base-Isolated and Top Floor (TMD-Type) Isolated Structural Frames

Therefore, in this paper POA method using standard UBC-97 code earthquake loading is only used for nonlinear analysis of the Without Isolation (WI) frame. However, the frame behavior under various earthquakes obtained from POA method is chosen as a basis for comparison of behavior of other isolated and non-isolated model frames under dynamic loading. Nonlinear Dynamic Analysis (NDA) of structures under earthquake has many complexities. Many researchers have used different earthquake accelerograms which has made comparison of the results very difficult. Nonlinear dynamic seismic analysis developed by using methods such as Time History Analysis (THA) and Incremental Dynamic Analysis (IDA) [6]. There methods are based on Standard Acceleration Spectrum together with various patterns of hysteresis cycles of structural response which has found wide applications in dynamic analysis due to the recent increase in speed and storage capacity of computers. During recent years the method of IDA, which employs gradually increasing acceleration amplitude in sequential THA is being used in seismic analysis of important structures [7]. It uses a large number of different time history accelerations (In some cases about 40 accelerograms) to obtain more reliable structural responses due to increasing levels of severity of earthquakes. In recent years, using Incremental Dynamic Analysis (IDA) method, which combines a set of spectra and generates results that are based on probability calculations, is often used in research works [3].

3- In this paper NDA in the form of step by step increasing amplitude of accelerograms are used to obtain dynamic results in the form P- $\Delta$ curves similar to POA method in the NSA approach for all model frames. For this purpose, two accelerograms are selected namely $1979 \mathrm{El}$ Centro earthquake and innovative accelerogram which is called FEMA 461-AA. These two accelerograms are described below and in sections 4-3-1 and 4-3-2 respectively. Another goal of this study is to develop and propose a new simple approximate accelerogram for NDA, on similar level of approximation simplicity and comparability with POA method which uses fictitious code given lateral seismic loading. The stepwise increasing loading in POA method does not reflect the dynamic and hysteretic characteristic of structures and the reciprocal nature of seismic earthquake induced loading. The proposed simple base acceleration should have the ability of reciprocal and dynamic properties of loading and emanate different hysterical properties of structure and can be used in analysis of structural isolation cases. This newly proposed method with incrementally increasing amplitude of reciprocal base acceleration is named Pushunder Analysis (PUA). This name is chosen because it is similar to pushing or pulling ground from under the structure with increasing acceleration. This proposed accelerogram is applied to non-isolated and isolated structures. Advantages and disadvantages of this proposed accelerogram are evaluated in this paper. It is hoped that this new approximate dynamic analysis (PUA method) can have the ability to compete with POA method and can be used for approximate nonlinear dynamic seismic analysis of conventional structures.

\section{The Concept of Base and Roof Isolation}

The essential goal of seismic isolation is to introduce horizontally flexible but vertically stiff components between the structure and ground which substantially uncouple the superstructure from high-amplitude and unwanted frequencies of earthquake shaking. The essential idea of base isolation is to extend the natural period of isolated part of the buildings. Erickson and Altoontash [8] reviewed the design and construction process of base isolation industrial buildings together with focus on: code requirements, design analytical methodologies and constructability challenges, where the complexity of Non-Linear Time History Analysis (NL-THA) and the fact that the superstructure often needs to effectively remain elastic and receives lower acceleration below its assigned fragility threshold was the main challenges. Jamalzadeh and Barghian [9] studied pendulum isolator systems. In their paper the effect of horizontal and vertical component of seismic effects were studied. Their results showed that earthquake vertical acceleration causes an increase in the isolator acceleration response which in turn causes an increase in the vertical and lateral acceleration [9]. The idea of using the roof or upper floor of tall buildings as TMD has gained popularity during past decades. In order to develop this type of TMD, it is necessary to isolate the roof or top floors of structure from its remaining lower part. Many researchers in the last three decades such as Warburton [10] and Sadek et al. [11] have developed modern effective methods for selection of optimal parameters of TMD systems. The improvement of seismic performance according to Nawrotsky [12] was confirmed by theoretical and practical investigations. Mechanisms for Seismic isolators between floors are described by Kelly and Naeim [1] in terms of using different types of Dampers-Isolators between floors. In this research, the friction pendulum Damper-Isolators was used for modeling which has the following features:

1. It should allow lateral movement in all direction with respect to upper floor as calculated.

2. It should meet the required energy absorption by friction characteristic and also should convert some of the kinetic energy of the earthquake to potential energy by increasing the height of the upper floor with respect to the lower floor in movement in every direction.

3. It should have suitable edges so that limits the amount of deformation to within defined limits.

4. It should connect the upper floor to the lower floors 
with such Pre-stressed cables so that it prevents uplift and possible collapse of the upper floor in severe earthquakes.

5. It should provide proper mechanism to pass pipes, elevator, shafts, equipment and canals between floors. The general shape of these isolators should be in the form of a symmetrical flexible hyperbolic cup in both directions and have proper frictional design properties.

Using supplemental dampers for vibration reduction has been frequently investigated in the past few decades. Various damping devices were proposed in order to improve the structural response to earthquakes and to limit the damage caused to the structural elements. These devices dissipate energy in various ways, such as by yielding of mild steel as proposed by Tyler [13] and Tsai et al. [14], sliding friction by Pall et al. [15], viscoelastic behavior of polymers by Bergman et al. [16], movement of a piston in viscous fluid by Constantinou and Fenz [4] and Symans [6]. Roof seismic isolation can be designed as a special type of TMD. Villaverde and Mosqueda [17] proposed that in order to overcome the disadvantages of conventional TMD systems which often require the use of relatively large mass, need vast space for installation, have large relative displacements of the mass which is caused by resonance which sets in vibration in comparable with the structures dominant frequency. The idea was to use a portion of the roof mass as the mass of the damper. Elastomeric bearings were used in base isolation systems by Kelly [18] who proposed them to be used together with viscous dampers instead of springs in order to reduce the mass displacement and to provide additional energy dissipation. Later on Villaverde [19] investigated a 13 story building to gain insight into the size of the bearings and the dampers needed to build an absorber and to estimate the maximum roof displacement and to prove the effectiveness of the proposed solution.

\section{Introduction of Two-Dimensional Model Frame}

\subsection{Statical and Dynamical Properties of Model Frames}

For structural modeling a ten story three bays two-dimensional braced steel frame as shown in Figure 1(a) is used. The design of members of the structure of this frame was obtained by designing this structure as Without Isolation frame under UBC-97 loading for Allowable Strength Design (ASD). The steel properties for the construction of the members of all isolated frames are similar to those obtained for Without Isolation frame as specified above. Four types of frames investigated in this paper are as follows: 1-fixed based or Without Isolation (WI), 2- Roof Isolation (RI), 3- Two Top Floor Isolation (2TFI) and 4- Base Isolation (BI). These models were used for comparative investigations. Due to symmetricity of the building, all internal frames as shown in Figure 1(b) in both directions of the building are similar and all external frames are braced frames as shown in Figure 1(c). Only the structural behavior of one of the 2D external braced frame is investigated in this paper. Lateral load of each floor of the building is assumed to be carried by two external frames on each side. The internal frames are assumed to carry their share of vertical loads and not carry any lateral load. The floors are all assumed to be rigid.

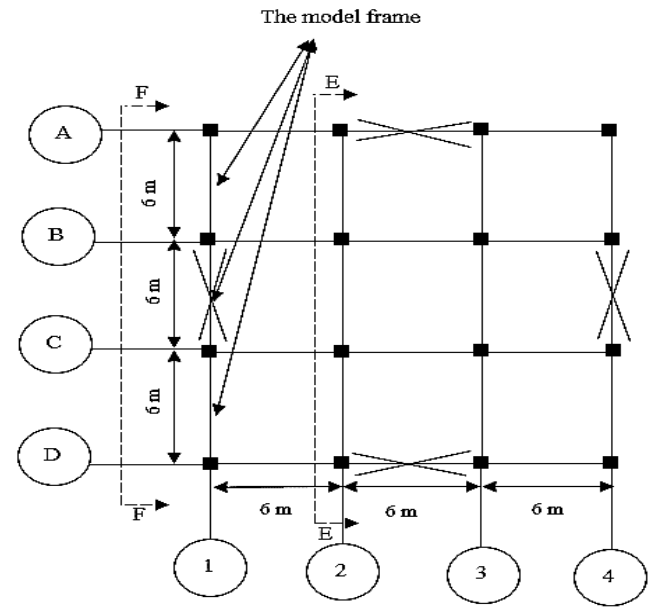

(a) Plan of the model building

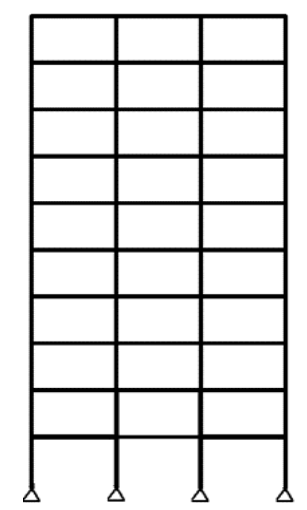

(b) Interior section E-E (Typ.)

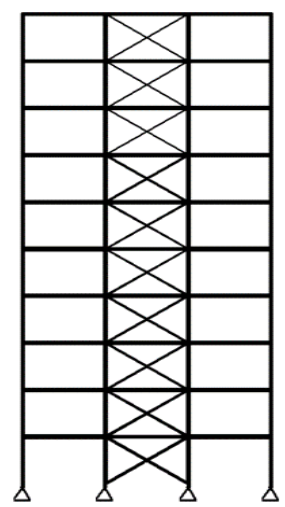

(c) Exterior frames F-F (Typ. model frame)

Figure 1. General arrangements of the model building 
The seismic behaviors of this model frame are: the total and relative drift of each story and shear load of each story which are shown by appropriate diagrams. In order to consider the effect of various vibration modes of the model frame, the linear dynamic modal analysis is used to obtain various time periods of each modes, and their corresponding percentage of mass participation. These values are shown in Table 1. Also the section properties of the structural members

of the frame such as columns, beams and bracings for each floors are shown in Table 2. The type of steel is assumed to be ST-37 with yield value of $24000 \mathrm{~N} / \mathrm{Cm}^{2}$ and the nonlinear dynamic behavior of steel members under reciprocating loads are based on elastoplastic pattern of the simple two-line behavior (kinematic) hysteresis loop shown by UBC-97-ASD [21].

Table 1. Frame Frequencies and their corresponding percentage of mass participation for eight modes of vibration of the ten story model steel Frame

\begin{tabular}{|c|c|c|c|c|c|c|c|c|}
\hline \multirow{2}{*}{ Periods and Percent Mass Participation Frames } & \multicolumn{7}{|c|}{ Modes } \\
\cline { 2 - 9 } & 1 & 2 & 3 & 4 & 5 & 6 & 7 & 8 \\
\hline Period T in seconds WI & 0.93 & 0.31 & 0.194 & 0.152 & 0.137 & 0.094 & 0.089 & 0.053 \\
\hline Percent mass participation WI & $81 \%$ & $12 \%$ & $2.1 \%$ & $1.7 \%$ & $0.62 \%$ & $0.43 \%$ & $0.36 \%$ & $0.273 \%$ \\
\hline Period T in seconds RI & 1.1 & 0.37 & 0.21 & 0.16 & 0.122 & 0.098 & 0.092 & 0.042 \\
\hline Percent mass participation RI & $89 \%$ & $7.2 \%$ & $1.7 \%$ & $0.9 \%$ & $0.51 \%$ & $0.26 \%$ & $0.12 \%$ & $0.11 \%$ \\
\hline Period T in seconds 2TFI & 1.33 & 0.44 & 0.22 & 0.17 & 0.141 & 0.101 & 0.091 & 0.062 \\
\hline Percent mass participation 2TFI & $88 \%$ & $8.2 \%$ & $1.8 \%$ & $0.75 \%$ & $0.61 \%$ & $0.26 \%$ & $0.22 \%$ & $0.07 \%$ \\
\hline Period T in seconds BI & 3.2 & 0.66 & 0.33 & 0.21 & 0.071 & 0.067 & 0.044 & 0.036 \\
\hline Percent mass participation BI & $99.97 \%$ & $0.02 \%$ & $0.007 \%$ & $0.002 \%$ & 0 & 0 & 0 & 0 \\
\hline
\end{tabular}

Table 2. Steel profile used in construction of WI frame and each exterior model frame

\begin{tabular}{|c|c|c|}
\hline Element & Story & Section \\
\hline \multirow{3}{*}{ Beams } & From 7 to 10 & IPB 260 \\
\cline { 2 - 3 } & From 1 to 6 & IPB 280 \\
\hline \multirow{3}{*}{ Columns } & From 8 to 10 & IPB 280 \\
\cline { 2 - 3 } & From 4 to 7 & IPB 300 \\
\cline { 2 - 3 } & From 1 to 3 & IPB 360 \\
\hline \multirow{3}{*}{ Braces } & From 9 to 10 & TUBE $139.7 \times 4$ \\
\cline { 2 - 3 } & From 8 to 6 & TUBE $168.3 \times 4.5$ \\
\cline { 2 - 3 } & From 5 to 3 & TUBE $168.3 \times 6.3$ \\
\cline { 2 - 3 } & From 2 to 1 & TUBE $193.7 \times 5.4$ \\
\hline
\end{tabular}




\subsection{The Properties of Friction Pendulum System (FPS) Used for Floors and Base Isolations}

Friction Pendulum System (FPS) is a friction isolation system which creates slipping and returning force due to its special geometry. A typical FPS isolator is schematically shown in Figure 2, which has a joint slider on a spherical stainless steel surface. One side of this join slider, is in contact with spherical surface, and is covered with low friction materials; the other side is covered with stainless steel. By moving the slider on spherical surface, its mass is lifted upside which produces a restoring force. Friction between sliding surface and spherical surface also produces friction damping in isolators. There are a few factors in design of Single Concave Friction Pendulum (SCFP) bearings such as the radius of curvature of the isolator surface $\left(\mathrm{R}_{\mathrm{FPS}}\right)$, friction coefficient of isolator surface $(\mu)$ and the surface dimensions. The typical general arrangement and technical characteristic properties of FPS are discussed by Kelly (1999). Table 3 gives the technical properties of all isolators used in this study which is calculated using Kelly's methodology [1].

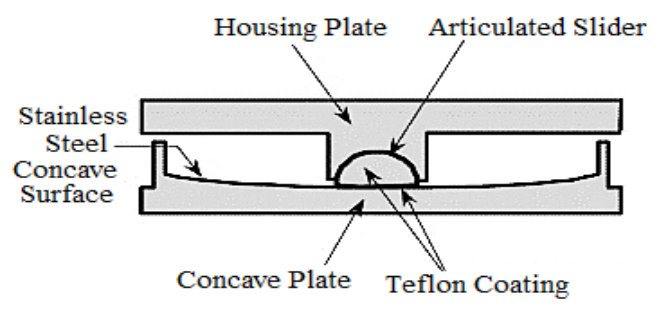

(a) Curved and spherical friction pendulum section cut [22]

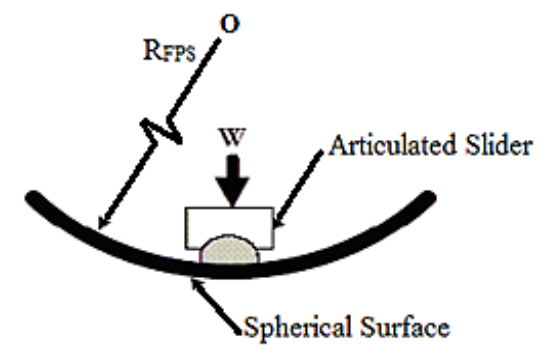

(b) Forces acting on the articulated slider in friction pendulum bearing [23]

Figure 2. Typical form of Friction Pendulum System isolators

Table 3. Technical properties of each SCFP link elements (isolators) calculated using Kelly's methodology in SAP 2000 structural analysis

\begin{tabular}{|c|c|c|c|}
\hline & BI & RI & 2TFI \\
\hline $\mathrm{R}_{\mathrm{FPS}}(\mathrm{m})$, curvature radius of isolator surface & 8.95 & 2.24 & 2.24 \\
\hline $\mathrm{h}(\mathrm{mm})$, height of bearing & 300 & 300 & 300 \\
\hline W (ton), equivalent of column load carried by isolators & 734 & 73.4 & 146.8 \\
\hline $\mathrm{K}_{\mathrm{v}}$ (ton/m), vertical stiffness of each isolators bearing & 2558500 & 2558500 & 2558500 \\
\hline $\mathrm{K}_{\text {elastic }}$ (ton/m), elastic stiffness of each isolators bearing & 13762.5 & 1376.5 & 2737.5 \\
\hline $\mathrm{K}_{\mathrm{eff}}(\mathrm{ton} / \mathrm{m})$, effective lateral stiffness of each isolators bearing & 61.81 & 16.46 & 32.74 \\
\hline 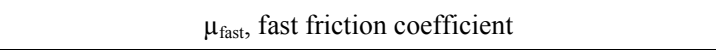 & 0.15 & 0.15 & 0.15 \\
\hline$\mu_{\text {slow }}$, slow friction coefficient & 0.1 & 0.1 & 0.1 \\
\hline Rate parameter (sec/m) & 100 & 100 & 100 \\
\hline
\end{tabular}




\section{Applied Loadings and Accelerations}

The following Static loading and dynamic base accelerations are applied to the model frames.

\subsection{Gravity Loads}

Dead Load per meter on the beams of each story and roof of the frames are: $3450 \mathrm{kgf} / \mathrm{m}$ and $3780 \mathrm{kgf} / \mathrm{m}$ respectively. Live load on the beams of each story and roofs are: $1800 \mathrm{kgf} / \mathrm{m}$ and $1350 \mathrm{kgf} / \mathrm{m}$ respectively. In calculation of seismic load only $25 \%$ of floor live load is considered.

\subsection{Applied Equivalent Static Lateral Loading Based on UBC-97 Seismic Code}

In this study the equivalent linear static lateral loads as represented by UBC-97 code [24] used for estimating base shear, story shear loads and drifts and also for determination of distribution of lateral forces at the height of the frames. The total and relative drift of the model frame was checked against to the code limitations. The total design base shear in Equation (1) in a given direction is determined from UBC-97 code as follows:

$$
\begin{gathered}
V=\frac{C_{V} I}{R T} W= \\
\frac{0.3 \times 1}{5.6 \times 0.93} \times 734.7=42.32 \text { tonf }
\end{gathered}
$$

Where $C_{v}=0.3$ is the velocity seismic coefficient, $C_{a}=$ 0.3 is the acceleration seismic coefficient related to $\mathrm{S}=$ $\mathrm{S}_{\mathrm{B}} \cdot \mathrm{S}_{\mathrm{B}}$ is coefficient relating to the type of the soil profile, $\mathrm{Z}$ $=0.3$ is the seismic zone factor, $\mathrm{I}=1$ is the building importance factor, $\mathrm{R}=5.6$ is the code specified reduction factor. $\mathrm{W}=734.7$ tonf is the total dead load plus $25 \%$ live load.

\subsection{Base Acceleration}

Two types of accelerograms were used for THA in this paper: The El centro earthquake acceleration 1979 (Elc 79) which is discussed in section 4.3.1 and a newly proposed fictitious acceleration FEMA 461 Analogous Accelerogram (FEMA 461-AA) which is presented in section 4.3.2. The basic properties of the response spectra of these accelerograms are shown in Table 4 and Figure 3 which represents the response spectrum at DBE level in UBC-97 where semi-dynamic loads are scaled according to design response spectra with $5 \%$ damped spectra of the ground motions and the target design spectrum as shown. The scale factors which are shown in Table 4 are obtained using the methodology described in section 1631.6 of UBC-97 code.

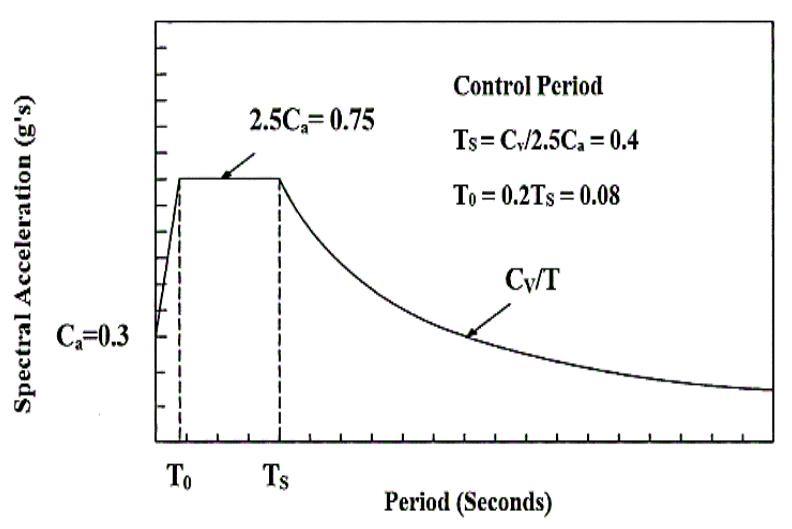

Figure 3. Design UBC-97 Response Spectra [24]

Table 4. DBE level base accelerations used for dynamic analysis of all

\begin{tabular}{|c|c|c|c|}
\hline Code & $\begin{array}{c}\text { Description and Figure } \\
\text { number }\end{array}$ & Frame & $\begin{array}{l}\text { PGA } \times \\
\text { Scale } \\
\text { Factor } \\
(\text { DBE) }\end{array}$ \\
\hline \multirow{4}{*}{ Elc 79} & \multirow{4}{*}{$\begin{array}{c}\text { El centro (Imperial Valley } \\
\text { (Array \#11) 1979), shown } \\
\text { in Fig } 4\end{array}$} & WI & 0.26 \\
\hline & & RI & 0.26 \\
\hline & & 2TFI & 0.26 \\
\hline & & BI & 0.28 \\
\hline \multirow{4}{*}{$\begin{array}{c}\text { FEMA } \\
461-A A\end{array}$} & \multirow{4}{*}{$\begin{array}{c}\text { FEMA 461- Analogous } \\
\text { Acceleration, shown in } \\
\text { Fig } 6\end{array}$} & WI & 0.151 \\
\hline & & RI & 0.159 \\
\hline & & 2TFI & 0.164 \\
\hline & & BI & 0.57 \\
\hline
\end{tabular}
frames

\subsubsection{El centro-1979 Time History Analysis (THA)}

Time history analysis (THA) is an important technique for dynamic seismic analysis of structures in linear and nonlinear ranges and for verification of the degree of accuracy of other approximate statical methods. THA is a step-by-step analysis of the dynamic response of a structure to a specified accelerogram and is used to determine the seismic response of structures under dynamic loading of representative earthquakes. To perform such an analysis in this paper, the acceleration of El Centro1979 earthquake (Elc 79) as shown in Figure 4.

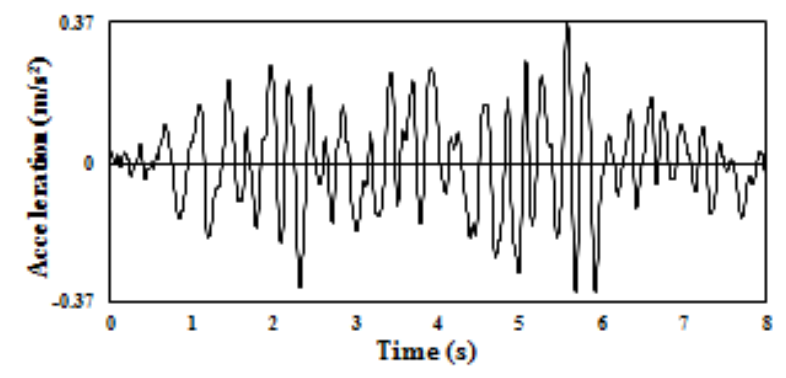

Figure 4. (Elc 79) Scaled Record of El Centro 1979 (E-W) accelerations from Peer (2010) [25] 
4.3.2. The Newly Proposed Fictitious Accelerogram Called FEMA 461 Analogous Accelerogram Used for Time History Analysis (FEMA 461-AA)

One of the semi-dynamic nonlinear tools which is used for testing structural members under reciprocal loading is proposed by FEMA 461. It uses incrementally increasing cyclic displacement, as shown in Figure 5. This displacement control loading is often used for experimental verification of strength and stress analysis of structural elements [26]. Similar experimental diagram for displacement control for structural member was proposed by Razani [27] in the past which uses increasing multiples of yielding displacement in Fibonacci steps and reciprocal patterns for testing reinforced concrete members and for presentation of test results. In the FEMA 461 diagram the ordinate shows the ratio of $\mathrm{d}_{\mathrm{i}}$ to $\Delta_{\mathrm{m}}$ where di is the i-th amplitude of the displacement cycles and $\Delta_{\mathrm{m}}$ is the maximum amplitude of the assumed objective displacement [26]. The horizontal axis shows the number of cycles of various amplitudes [26]. The number of steps $\mathrm{N}$, (a value of $\mathrm{N} \geq 10$ is recommended) shows the number of reciprocal cycles [26]. Two sequential cycles are executed having the same amplitude [26].

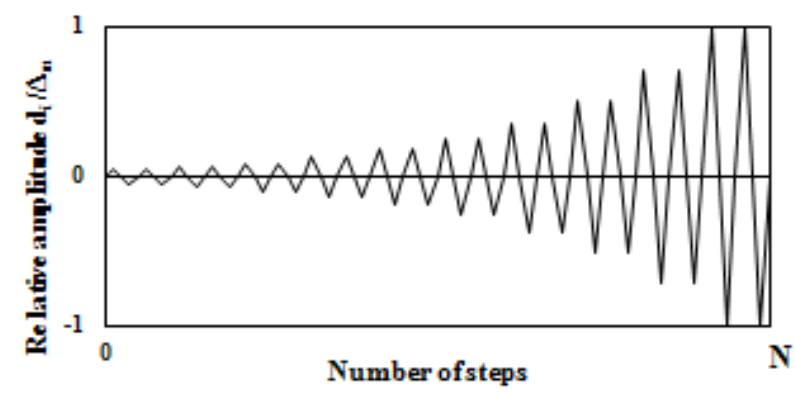

Figure 5. Recommended step-wise increasing displacement cycles for testing structural elements by FEMA 461[26]

In this paper an innovative fictitious base acceleration pattern similar to FEMA 461 displacement cyclic pattern shown in Figure 6 is presented which instead of applying cyclic displacement to the element being tested; it applies analogous, similar shape cyclic acceleration with specific amplitude to the base of the frame.

The reason for choosing this pattern of base acceleration is the similarity of the oscillation amplitude of displacement of Single Degree Freedom (SDF) mass-spring systems with acceleration of those systems during sinusoidal cyclic vibration. In this proposed method the amount of acceleration which is applied to the base of structure is increasing from zero to a maximum amount specified for the Design Base Earthquake such as DBE or MCE levels.

This novel base acceleration was proposed as a new approximate approach to be used in lieu of fictitious standard UBC-97 code loading pattern used in NSA by POA. This new acceleration patterns while keeping many facets of dynamical loading such as hysteretic damping produced during reciprocal dynamic displacement, it also makes possible the use of accepted displacement pattern used by FEMA 461 for reciprocal testing of structural elements for analogous THA of the entire structure.

Therefore, the existing software for THA can be used for nonlinear analysis of the entire structure using the proposed base acceleration patterns. The comparative usefulness of this proposed simple pattern which shall be called FEMA 461-AA (Analogous Accelerogram) is evaluated in this paper. For dynamic analysis of the model frames the duration of testing is assumed 8 seconds which is the duration of 20 cycles of oscillation of structure by the pattern shown in Figure 6. The maximum number of oscillation $\mathrm{N}$ is assumed 20 . The frequency of oscillation for general structures is to be taken equivalent $T_{a v e}$ in Equation (2) where:

$$
\mathrm{T}_{\mathrm{ave}}=\frac{\sum_{\mathrm{i}=1}^{\mathrm{n}} \mathrm{T}_{\mathrm{i}} \mathrm{M}_{\mathrm{i}}}{\sum_{\mathrm{i}=1}^{\mathrm{n}} \mathrm{M}_{\mathrm{i}}}
$$

$\mathrm{T}_{\mathrm{i}}$ and $\mathrm{M}_{\mathrm{i}}$ are the modal period and the mass participation of the $\mathrm{i}$-th mode respectively and $\mathrm{M}_{\mathrm{T}}$ is the total mass of the structure. The number of modes that is considered in this Equation (3) is such that the sum of the percentage of mass participation exceeds $90 \%$ of the total mass of the structure $\left(\mathrm{M}_{\mathrm{T}}\right)$.

$$
\sum_{\mathrm{i}=1}^{\mathrm{n}} \mathrm{M}_{\mathrm{i}} \geq 0.9 \mathrm{M}_{\mathrm{T}}
$$

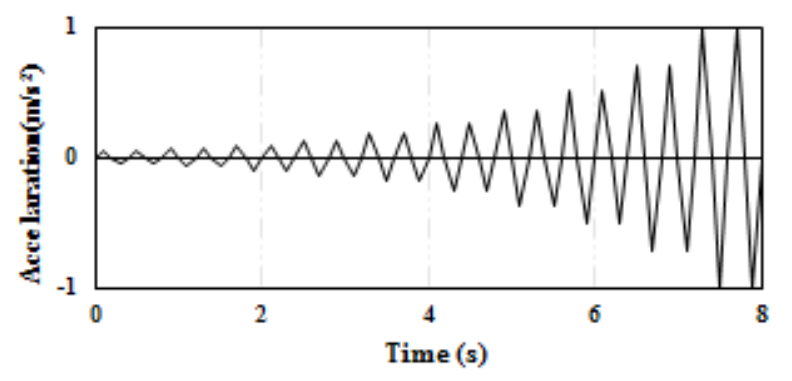

Figure 6. (FEMA 461-AA) Time history of proposed cyclically increasing base acceleration

\section{Analysis and Discussions of Results in Linear, Non-Linear and Dynamic Levels}

\subsection{Linear Case}

In this section maximum total and relative lateral drifts of roof and floors of the model frames and their story shears are obtained under different loads and base acceleration in linear range as specified for WI frame.

These results are compared with each other (all frames under Elc 79 and FEMA 461-AA) and with similar results obtained under UBC-97code specified loading for WI frame are shown in Figure 7,8 and 9 as described below. 


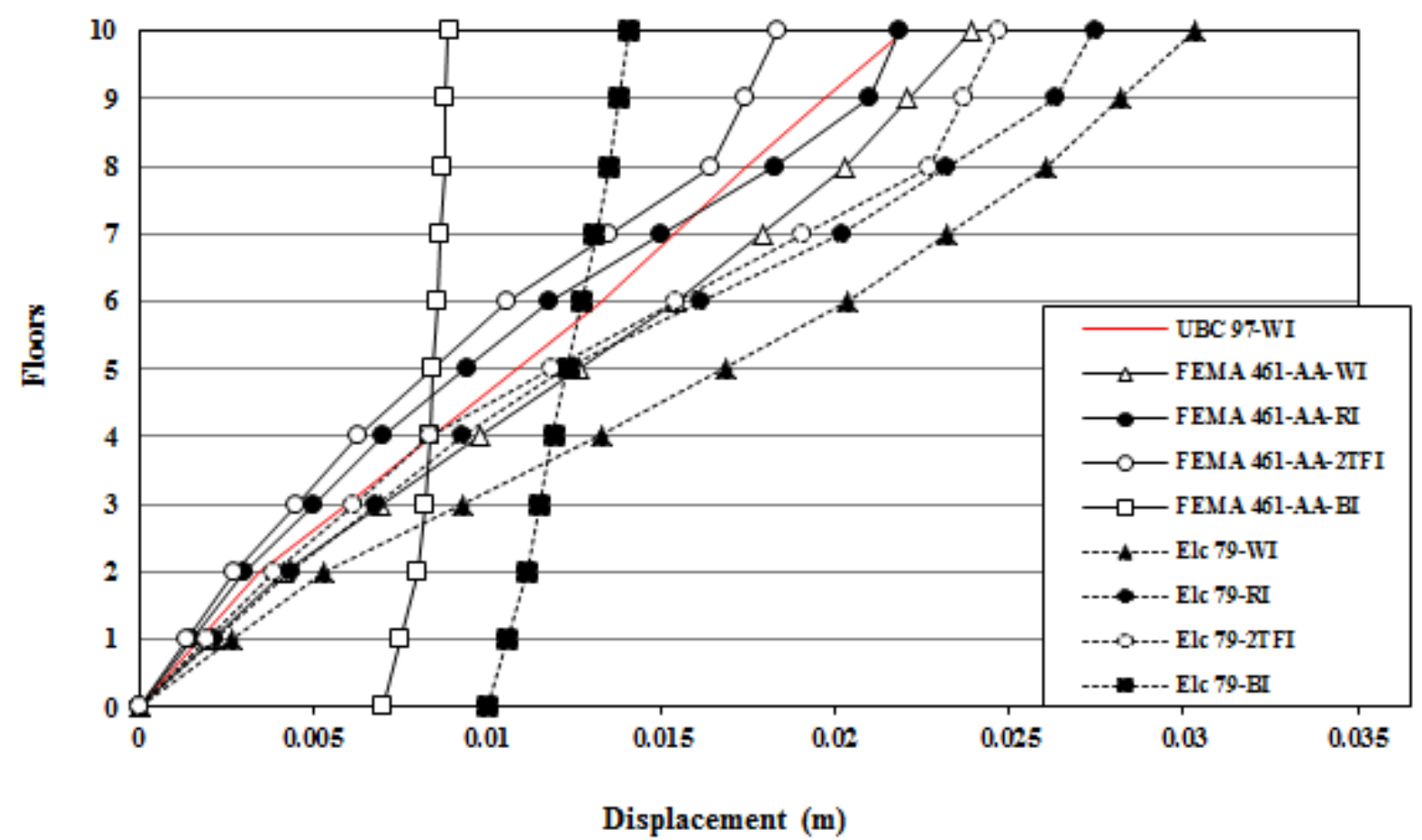

Figure 7. Max total floor displacement of all floors of various model frames under applied lateral UBC-97 code loading, FEMA 461-AA and El 79 base accelerograms

\subsubsection{Comparison of Maximum Total Displacement of Floors for Various Frames}

Figure 7 shows the maximum total displacement responses of various floors of the model frame due to the applied loading and accelerations. The roof displacement of RI and 2TFI frames under FEMA 461-AA are less than those under Elc 79 acceleration, but they are very close to UBC-97 displacement for WI frame.

The roof displacement of them are approximately $15 \%$ $17 \%$ and $20 \%$ - 25\% less than WI frame respectively, Similarly, the roof displacement of BI frame is $60 \%-65 \%$ less than WI frame under FEMA 461-AA and Elc 79 respectively.

\subsubsection{Comparison of Maximum Relative Drift of Floors} for Various Frames
Figure 8 shows the maximum relative lateral drift responses of various floors of the model frames. The responses of the BI frame under FEMA 461-AA and WI frame under UBC-97 and FEMA 461-AA underestimate similar response under Elc 79.

However, the response WI frame under FEMA 461-AA is closer to UBC-97. The response of RI and 2TFI frames under Elc 79 and FEMA 461-AA are underestimate the response of WI frame under UBC-97, however, for lower floors, they are overestimate on the upper floors.

The relative drift of WI frame under Elc 79 is higher than that of same frame under FEMA 461-AA.

Also, the relative drift of all floors of WI frame under FEMA 461-AA lies between those obtained for UBC-97 and Elc 79. Furthermore, the lateral drift of all floors of BI frame are significantly less than those other of frame. 


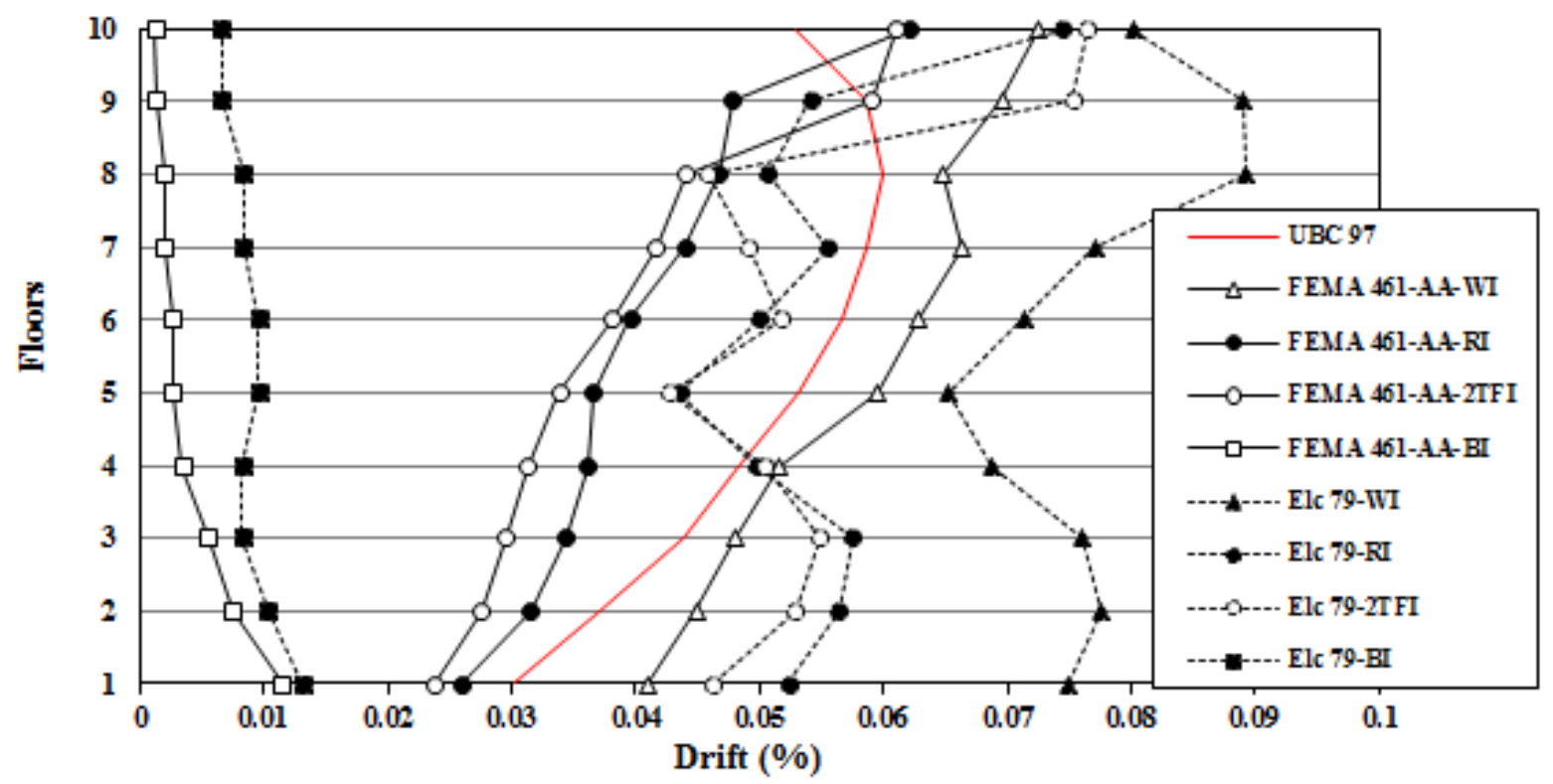

Figure 8. Max relative drift of all floors of various model frames under applied lateral UBC-97 code loading, FEMA 461-AA and El 79 base accelerograms

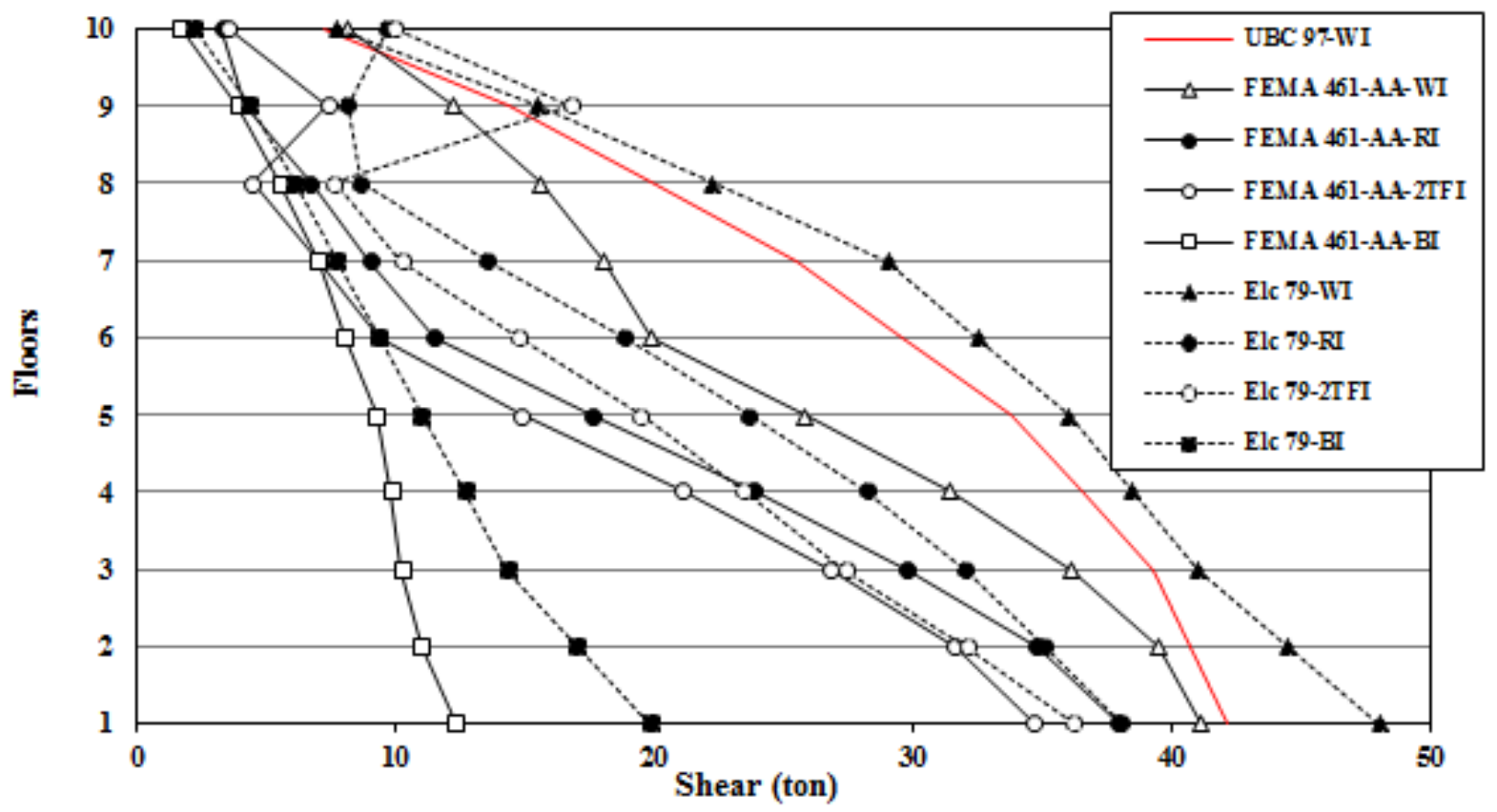

Figure 9. Max floor shear of all floors of various model frames under applied lateral UBC-97 code loading, FEMA 461-AA and El 79 base accelerograms 


\subsubsection{Comparison of Story Shear Forces and Maximum Base Shears for Various Frames}

Figure 9 shows the maximum shear responses of various floors of the model frames. The base and floors shears of WI frame under Elc 79 overestimate those under UBC-97. The base and floors shears of the rest of the frame under all loading underestimate those under UBC-97.

The responses of WI frame under FEMA 461 is very close to UBC-97, however, between fourth and eighth floor the differences with UBC-97 responses is significantly increased. For BI frame under Elc 79 and FEMA 461-AA the floors shear of this frame under FEMA 461-AA is less than that of Elc 79 and both of them are significantly less than similar response of other frames under specified loading and acceleration as shown in Figure 9. The responses of RI and 2TFI frames under Elc79 and FEMA 461-AA are approximately $25 \%-20 \%$ and $30 \%-20 \%$ less than WI frame respectively, Similarly, the responses of BI frame are $65 \%-70 \%$ less than WI frame under Elc79 and FEMA 461-AA respectively.

\subsection{Comparison of Non-Linear: (Statical (POA) and Dynamical (PUA)) Responses of Various Frames under Specified Loading and Acceleration}

For nonlinear analysis of WI frame the conventional
POA method by using stepwise increasing lateral load given by UBC-97 code was used. For nonlinear analysis of the behavior of isolated frames a method similar to Nonlinear Time History Analysis (NTHA) with stepwise increasing amplitude of base acceleration was applied using Elc 79 and FEMA 461-AA where the conventional P- $\Delta$ curves were transformed to $S_{a}$ vs. $S_{d}$. In this curves $S_{a}$ is obtained by dividing base shear by total mass of the structure and $S_{d}$ is roof displacement. Figure 10 and Figure 11 show that:

1. BI frame under Elc 79 and FEMA 461-AA can resist earthquakes with higher intensity than DBE and MCE levels.

2. All frames can resist DBE level earthquake but 2TFI frame is stronger than RI frame, and both of them have high strengths than that predicted by UBC-97. WI frames under Elc 79 and FEMA 461-AA show less resistant than UBC-97.

3. In all cases, the resistant of all frames under FEMA 461-AA is more than that predicted under Elc 79 in linear range. And in nonlinear range, this trend is reversed and FEAM 461-AA prediction curves are under Elc 79 curves.

4. Except for BI frame, the rest of the frames cannot resist MCE earthquake level. However, the RI and 2TFI frames have more resistant than WI frame under UBC-97, Elc 79 and FEMA 461-AA.

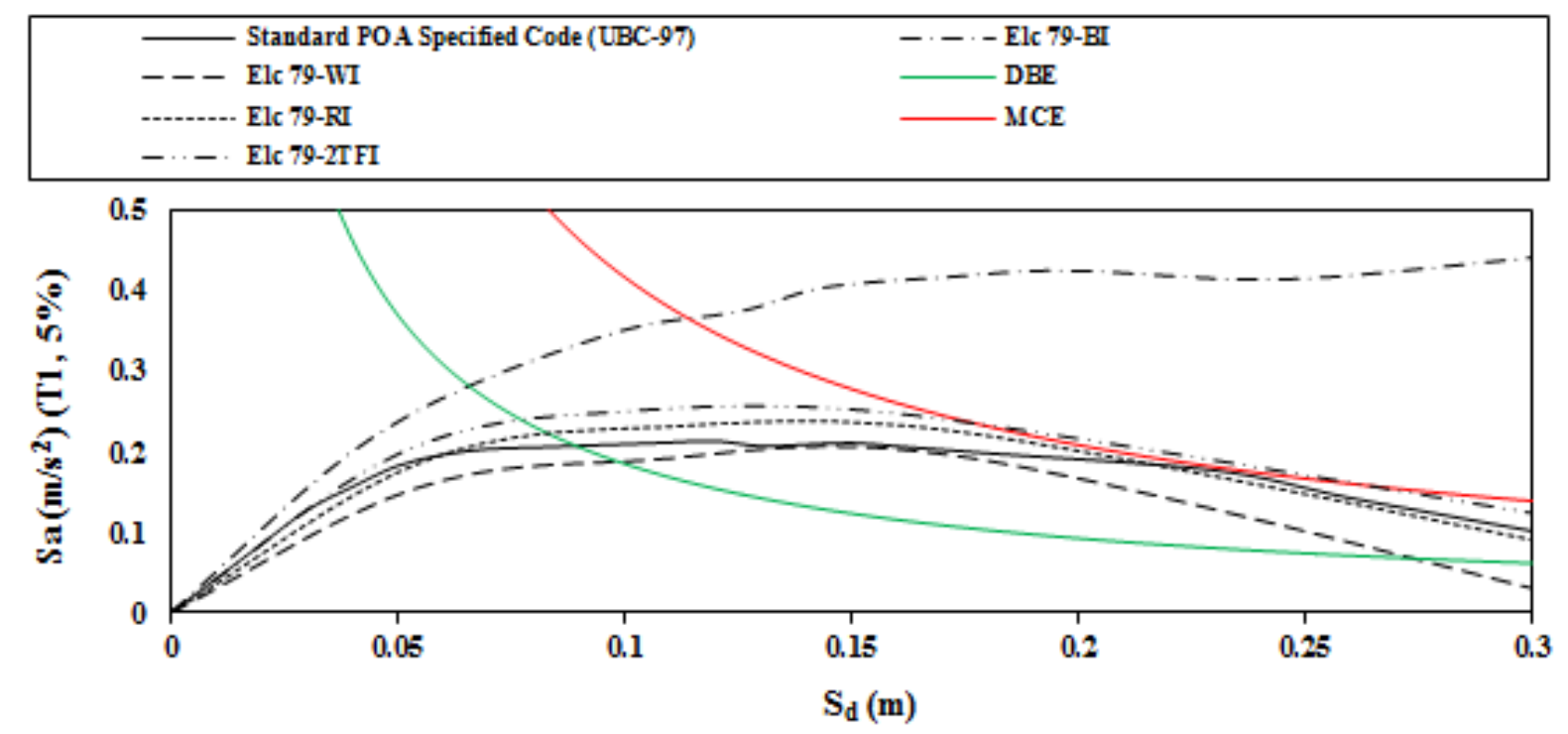

Figure 10. $\mathrm{S}_{\mathrm{a}}$ vs $\mathrm{S}_{\mathrm{d}}$ curves (P- $\Delta$ ) for the all model frames under applicable standard POA loading and Elc 79 

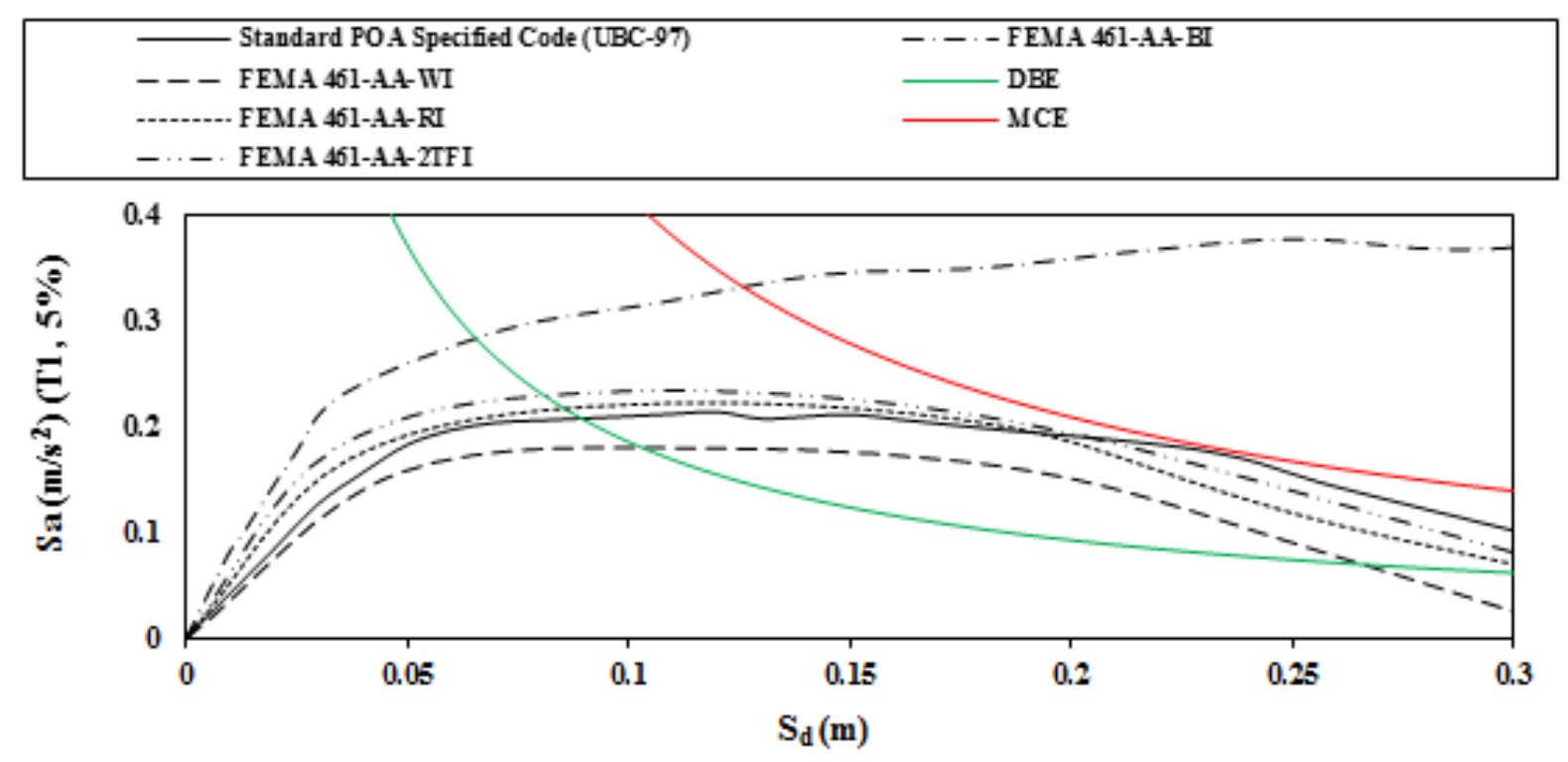

Figure 11. $\mathrm{S}_{\mathrm{a}}$ vs $\mathrm{S}_{\mathrm{d}}$ curves (P- $\Delta$ ) for the all model frames under applicable standard POA loading and FEMA 461-AA

\section{Conclusions}

In this study, the total and relative drift of each story and shear load of each building floors, at linear level for each of the frames: Without Isolation, Base Isolation, Roof Isolation and Two Top Floor Isolation frames under both FEMA 461-Analogous Accelerogram (FEMA 461-AA) and El centro -1979 (Elc 79) were obtained. The following conclusions are observed:

1. Roof isolation and two top floor isolation frames are able to reduce significantly lateral displacement floors compare to without isolation frame.

2. Roof isolation frame is able to reduce considerably the floors shear forces in comparison to without isolation frame but it is not competitive with the base isolation frame.

3. Base isolation frame, two top floor isolation frames and roof isolation frame respectively perform well than to without isolation frame.

4. Lateral drift studies of the model frames show that using FEMA 461-AA can predict better the possibility of damage of various floors than those obtained using conventional POA method. Also, the damage on the upper floors is potentially more than lower floors in most cases.

5. As far as isolation systems are concerned the responses of linear and nonlinear ranges, the base isolation frame is superior to roof isolation frame. Two top floor isolation frames have superior behavior than roof isolation and without isolation frames under two accelerograms and also compare to without isolation frame under UBC-97 used.

6. The linear responses of all frames under FEMA 461-AA are closer to that under Elc 79 than the response shown under UBC-97. Therefore, in general, the FEMA 461-AA can be used in lieu of UBC-97 in PUA method of dynamic analysis of steel frames.
Comparison of responses of without isolation frame using pushover analysis and dynamic analysis under El Centro -1979 and FEMA 461-AA shows that in linear range the response under FEMA 461-AA is closer to El Centro -1979 than those obtained by pushover analysis. However, in nonlinear range pushover analysis overestimates both dynamic analyses. FEMA 46-AA underestimates both El Centro -1979 and pushover analyses. The response of base isolation frame under the two mentioned accelerograms is much higher than the response of other frame under same accelerograms. Also the responses of the two floor isolated is better than the rest of the frames. The responses of roof isolated frame are less than other isolated frames but better than without isolation frame under the two accelerograms.

The two dynamic responses of the two top floor isolation frames are closest to the response of without isolation frame under using pushover as compared to other frames.

The conclusion of this study is only concerned with the linear and nonlinear behavior of the ten story steel model frame used and it need further investigation to be used in other type of frames practices. It is recommended that this research be extended to low, mid and high-rise buildings and to different types of bracing system with various type of hysteretic behavior. Also, it is proposed that by using IDA methodology on evaluating the properties of real earthquake accelerograms a few simple fictitious accelerograms similar to FEMA 461-AA be created which using them could improve the simplicity and accuracy of the proposed semi-dynamic Pushunder Analysis (PUA) method.

\section{REFERENCES}

[1] J. M. Kelly and F. Naeim. Design of seismic isolated 
structures, New York: John Wiley and Sons, 1999.

[2] A. Shirayama, T. Yamashita, S. Mukai, Y. Baba, and Inoue, Y. Design proposal for controlling seismic behaviors of inter-story isolation building structures, 13th World Conference on Earthquake Engineering, Vancouver, B.C., Canada, August 1-6, 2004.

[3] M. H. Chey. Passive and semi-active tuned mass damper building systems, PhD Thesis. Dept. of Civil and Natural Resources Engineering, University of Canterbury, 2007.

[4] M. Constantinou and D. Fenz. Mechanical Behavior of Multi-Spherical Sliding Bearings, MCEER-08-0007, 2008.

[5] Y. Tsuneki, S. Torii, K. Murakami and T. Sueoka. Middle-story isolated structural system of high-rise building, The 14th World Conference on Earthquake Engineering, Beijing, China, October 12-17, 2008.

[6] M. D. Symans. Seismic protective systems: seismic isolation, Rensselaer Polytechnic Institute, FEMA 451, 2009.

[7] D. Harmpis and P. Komodromos. Optimized earthquake response of multi-story buildings with seismic isolation at various elevations, Earthquake Engineering and Structural Dynamic, 2012.

[8] T. W. Erickson and A. Altoontash. Base Isolation for Industrial Structures, Design and Construction Essentials, ASCE, Structures Congress, 1440-1451, 2010.

[9] A. Jamalzadeh and M. Barghian. Dynamic Response of a Pendulum Isolator System under Vertical and Horizontal Earthquake Excitation, Periodica Polytechnic, Civil Engineering, 59(3), 433, 2015.

[10] G. B. Warburton. Optimum absorber parameters for minimizing vibration response, 15 th International Congress of Theoretical and Applied Mechanics, Toronto, Canada, 1980 .

[11] F. Sadek, B. Mohraz, A.W. Taylor and R. M. Chung. A Method of Estimating the Parameters of Tuned Mass Dampers for Seismic Applications, Earthquake Engineering and Structural Dynamics, 26:6, 617 - 637, 1997.

[12] P. Nawrotsky. Tuned-Mass Systems for the Seismic Retrofit of Buildings, 7-th International Congress on Advances in Civil Engineering, Istanbul, Turkey, paper No. 056, 2006.

[13] R. G. Tyler. Further Notes on Steel Energy-Absorbing Element for Braced Frameworks, National Society for Earthquake Engineering, 18: 3,270-279. 1985.

[14] K. C. Tsai, H. W. Chen, C. P. Hong and Y. F. Su. Design of Steel Triangular Plate Energy Absorbers for Seismic-Resistant Construction, Earthquake Spectra 9:3, 505-528, 1993.

[15] A. Pall, S. Vezina, P. Proulx and R. Pall. Friction Dampers for Seismic Control of Canadian Space Agency Headquarters. Earthquake Spectra 9:3, 547-558, 1993.

[16] D. M. Bergman and R. D. Hanson. Viscoelastic Mechanical Damping Devices Tested at Real Earthquake Displacements, Earthquake Spectra, 9:3, 389-418, 1993.

[17] R. Villaverde, and G. Mosqueda. Aseismic Roof Isolation System: Analytical and Shake Table Studies, Earthquake Engineering and Structural Dynamics, 28:3, 217 - 234, 1999
[18] J. M. Kelly. Earthquake - Resistant Design with Rubber, Springer, London, 1993.

[19] R. Villaverde. Aseismic Roof Isolation System: Feasibility Study with 13 - Story Building, ASCE Journal of Structural Engineering, 128:2, 188 - 196, 2002

[20] Computers and Structures, Inc. SAP2000, version 7.4, Integrated structural analysis and design software. Berkeley, CA, 2000.

[21] H. Baghaei. Investigation of Seismic Behavior of Top Floor (Floors) Isolation of Structures to be Used as Tuned Mass Damper (TMD) and Comparison of Their Merits, M.S thesis, Advisor: Prof. Reza Razani, Dept. Civil Engineering, Islamic Azad University of Tehran- South Branch, Tehran, Iran, 2015.

[22] Nistir 5800, "Guidelines for Pre-qualification, Prototype and Quality Control Testing of Seismic Isolation System,”, 143. 1996.

[23] M. Prem Sai, Base Isolation Concept and Techniques, Technical seminar, 2015, available from: https://www.slide share.net/premsai05/base-isolation-45889743.

[24] International Building Code UBC. International building code council, ICC, 1997.

[25] PEER. Technical Report for the Ground Motion Database web, California Pacific Earthquake Engineering Research Center:http://peer.berkeley.edu/peer_ground_motion_datab ase, 2010

[26] FEMA. Interim Protocols for Determining Seismic Performance Characteristics of Structural and Nonstructural Components Through Laboratory Testing, FEMA 461 Draft document, Federal Emergency Management Agency, 2007

[27] R. Razani. Proposed standard method for dynamic testing of reinforced concert members and for a presentation of test result, In: Proceedings of the 6th world conference on frontiers of earthquake engineering, India, New Delhi, 3:2919-2921, 1977. 